\title{
Editorial
}

\section{COVID-19 and Children: Many Questions Yet To Be Answered}

Tiago Henrique de Souza, ${ }^{1} M D$, PhD, Vanessa Soares Lanziotti, ${ }^{2} M D$, PhD, Jan Hau Lee, ${ }^{3,4}{ }_{M B B S, M R C P C H, M C I}$

The world is currently facing the greatest public health challenge of the 21st century: the COVID-19 pandemic. This novel disease first emerged in December 2019, when an outbreak of pneumonia due to unknown etiology emerged in Wuhan, China. Since then, the infection caused by the severe acute respiratory syndrome coronavirus 2 (SARS-CoV-2) has affected more than 200 countries, resulting in excess of 26 million confirmed cases with 876,616 deaths (6 September $62020){ }^{1}$

To date, children have been spared from the worst health impacts of COVID-19. ${ }^{2}$ Compared to adults, absolute number, severity and mortality of confirmed pediatric cases remain low. ${ }^{3}$ Fortunately, only a small proportion of infected children becomes critically ill. At the end of July 2020, the cumulative number of child COVID-19 cases reported in United States were 338,982 (8.8\% of all cases) with 86 deaths. ${ }^{4}$ Some hypothesis that may explain why children have less severe disease are: lower angiotensin-converting enzyme 2 (ACE2) expression, possible antibodydependent enhancement (ADE) mechanism of the SARS-CoV-2 and/or immature adaptative immunity. ${ }^{5}$ Clinical manifestations of COVID-19 in children differ widely from adults, necessitating a high level of clinical suspicion to diagnose these children. ${ }^{6}$ About half of infected children may have no fever or respiratory symptoms. Gastrointestinal symptoms may occur early, which may be mistaken with other acute abdominal diseases, such as appendicitis. ${ }^{7}$ Younger age, obesity and presence of comorbidities have been shown to be risk factors for severe pediatric COVID-19 disease. ${ }^{3}$

By April 2020, reports of a novel Kawasaki disease-like multisystem inflammatory syndrome affecting children and adolescents emerged from
Europe and North America. ${ }^{8}$ In May, the Center for Disease Control and Prevention released a health alert describing this disease and labeled it as multisystem inflammatory syndrome in children (MIS-C), a rare severe condition that can manifest 2-4 weeks after the onset of COVID-19 in children and adolescents. Currently, MIS-C is generally considered as a different clinical entity from Kawasaki Disease. Children with MIS-C often present shock with cardiac involvement, gastrointestinal symptoms, increased inflammatory markers with positive laboratory test results for SARSCoV-2. ${ }^{9}$ MIS-C, however, have not been described in Asia. Reasons for this difference remain unclear. One plausible explanation may be related to the SARSCOV-2 genomic diversity resulting in different antigens presentation and individual genetic variation. ${ }^{10}$

In this issue of Annals Academy of Medicine, Singapore, Li et al evaluated the clinical, epidemiological and laboratory parameters of 39 children infected with SARS-CoV-2, which represented approximately $70 \%$ of all pediatric cases detected in Singapore by May 2020. ${ }^{11}$ Household transmission accounted for $95 \%$ of cases. All children had a mild disease, and none required oxygen supplementation or intensive care. In fact, $38.5 \%$ of the infected children were asymptomatic. The presenting symptoms of symptomatic children were low grade fever (54.2\%), rhinorrhea (45.8\%), sore throat $(25 \%)$, diarrhea $(12.5 \%)$ and acute olfactory dysfunction $(5.4 \%)$.

While this study corroborates with the current evidence that children with COVID-19 have good prognosis and favorable clinical course, it also raises concern about the role of children in the viral transmission chain. Since vast majority of children with COVID-19 are asymptomatic or have mild disease, they are less likely to be tested

\footnotetext{
${ }^{1}$ Pediatric Intensive Care Unit, Department of Pediatrics, Clinics Hospital of the State University of Campinas (UNICAMP), Campinas, SP, Brazil. ${ }^{2}$ Pediatric Intensive Care Unit \& Research and Education Division/Maternal and Child Health Postgraduate Program, Federal University of Rio de Janeiro (UFRJ), Rio de Janeiro, RJ, Brazil

${ }^{3}$ Children's Intensive Care Unit, KK Women's and Children's Hospital, Singapore ${ }^{4}$ Duke-NUS Medical School, Singapore

Address for Correspondence: Dr Jan Hau Lee, KK Women's and Children's Hospital, 100 Bukit Timah Road, Singapore 229899

Email: lee.jan.hau@singhealth.com.sg
} 
when compared to adults, leading to an underestimate of the true numbers of infected people. In addition, it has been observed that children younger than 5 years with mild to moderate COVID-19 have higher nasopharyngeal SARS-CoV-2 viral loads when compared to older children and adults which could potentially make children silent spreaders of the virus. ${ }^{12}$ However, there is little consensus among experts about the importance of children in the spread of COVID-19, and the prospect of reopening schools has increased the debate on this issue in several countries. The results presented by Li et al in this issue of Annals, suggest that many children with COVID-19 may return to school without being aware of their infection since they are asymptomatic. ${ }^{11}$ This is an important issue and should be considered when approaching school return during this pandemic. Locally in Singapore, the approach of reopening schools with the appropriate precautions (e.g., safe distancing, mask wearing and staggered opening of certain extracurricular activities) is a prudent one. The priority of school reopening is correctly placed in the overall approach of larger reopening of the economy.

As a result of this pandemic, it is estimated that $60 \%$ of students worldwide have their education disrupted. ${ }^{13}$ School closures are based on prior experience from influenza outbreaks, for which the transmission of the virus was largely driven by children. However, due to differences in the transmission dynamics, the same advantages may not be applicable in the COVID-19 pandemic. In fact, there are conflicting reports in this area. In Australia, where most schools have remained open during the first epidemic wave, a study evaluating SARS-CoV-2 transmission in 25 educational settings (primary and secondary schools, and early childhood education and care settings) found low incidence of children and staff members with COVID-19 and low rates of virus transmission. ${ }^{14}$ An analysis conducted in the United States performed between March and May 2020, showed that school closure was temporally associated with declined COVID-19 incidence and mortality, although, it remains possible that some of this decline may have been related to other concurrent interventions. ${ }^{15}$ In Israel, a major COVID-19 high school outbreak occurred only ten days after schools reopened. ${ }^{16}$ Laboratory testing revealed that 153 students (attack rate: 13.2\%) and 25 staff members (attack rate: 16.6\%) were infected. Indeed, there remains inconclusive data on the relative contribution of school closures to SARS-CoV-2 transmission control. However, as pediatricians, we must be mindful that schools provide meals, shelter, social and mental support for children. Bearing this in mind, in countries where school reopening is being debated, this must be planned carefully, with priority given to children's physical and mental health.

In conclusion, many children infected with SARSCoV-2 may not be identified because they are asymptomatic. Asymptomatic children with COVID-19 can potentially spread the virus, however, their importance in the transmission chain remains unclear. Accurately establishing the child's role in the pandemic is crucial to making appropriate public health decision.

\section{REFERENCES}

1. World Health Organization. Coronavirus Disease (COVID-19) Weekly Epidemiological Update. Data as Received by WHO from National Authorities, as of 10 Am CEST 6 September 2020; 2020. https://www. who.int/docs/default-source/coronaviruse/situation-reports/20200907weekly-epi-update-4.pdf?sfvrsn=f5f607ee 2 .

2. Chew SY, Lee YS, Ghimiray D, Tan CK, Chua GS. Characteristics and Outcomes of COVID-19 Patients with Respiratory Failure Admitted to a "Pandemic Ready" Intensive Care Unit - Lessons from Singapore. Ann Acad Med Singapore. 2020;49:434-448.

3. Ong JSM, Tosoni A, Kim Y, Kissoon N, Murthy S. Coronavirus Disease 2019 in Critically Ill Children: A Narrative Review of the Literature. Pediatr Crit Care Med. 2020;21(7):662-666. doi:10.1097/ PCC.0000000000002376

4. American Academy of Pediatrics. Children and COVID-19: state-level data report. https://services.aap.org/en/pages/2019-novel-coronaviruscovid-19-infections/children-and-covid-19-state-level-data-report/. Published 2020. Published 2020. Accessed September 6, 2020.

5. Lanziotti VS, de Souza DC, Marques ETA. Coronavirus Disease 2019: Understanding Immunopathogenesis Is the "Holy Grail" to Explain Why Children Have Less Severe Acute Disease. Pediatr Crit Care Med. 9000; Online Fir.

6. Goh KJ, Choong MC, Cheong EH, et al. Rapid Progression to Acute Respiratory Distress Syndrome: Review of Current Understanding of Critical Illness from COVID-19 Infection. Ann Acad Med Singapore. 2020;49(3):108-118

7. de Souza TH, Nadal JA, Nogueira RJN, Pereira RM, Brandao MB. Clinical manifestations of children with COVID-19: a systematic review. Pediatr Pulmonol. 2020;55(8):1892- 1899. doi:10.1002/ppul.24885

8. Riphagen S, GomezX, Gonzalez-Martinez C, Wilkinson N, Theocharis P. Hyperinflammatory shock in children during COVID-19 pandemic. Lancet. 2020;395(10237):1607-1608. doi:10.1016/S0140-6736(20)31094-1

9. Godfred-Cato S, Bryant B, Leung J, et al. COVID-19-Associated Multisystem Inflammatory Syndrome in Children - United States, March-July 2020. MMWR Morb Mortal Wkly Rep. 2020:ePub: 7 August 2020. doi:http://dx.doi.org/10.15585/mmwr.mm6932e2 
10. Kam K-Q, Ong JSM, Lee JH. Kawasaki disease in the COVID-19 era: a distinct clinical phenotype? Lancet Child Adolesc Heal. August 2020. doi:10.1016/S2352-4642(20)30207-8

11. J Li, KC Thoon, CY Chong, M Maiwald, K Kam, et al. Comparative analysis of symptomatic and asymptomatic SARS-CoV-2 infection in children. Ann Acad Med Singapore 2020;49:530-37.

12. Heald-Sargent T, Muller WJ, Zheng X, Rippe J, Patel AB, Kociolek LK. Age-related differences in nasopharyngeal severe acute respiratory syndrome coronavirus 2 (SARS-CoV-2) levels in patients with mild to moderate coronavirus disease 2019 (COVID-19). JAMA Pediatr. July 2020. doi:10.1001/jamapediatrics.2020.3651

13. United Nations Educational Scientific and Cultural Organization. COVID-19 educational disruption and response.
14. Macartney K, Quinn HE, Pillsbury AJ, et al. Transmission of SARS-CoV-2 in Australian educational settings: a prospective cohort study. Lancet Child Adolesc Heal. August 2020. doi:10.1016/S23524642(20)30251-0

15. Auger KA, Shah SS, Richardson T, et al. Association Between Statewide School Closure and COVID-19 Incidence and Mortality in the US. JAMA. July 2020. doi:10.1001/jama.2020.14348

16. Stein-Zamir C, Abramson N, Shoob H, et al. A large COVID-19 outbreak in a high school 10 days after schools' reopening, Israel, May 2020. Eurosurveillance. 2020;25(29). doi:https://doi. org/10.2807/1560-7917.ES.2020.25.29.2001352 